\title{
Development and application of inverse heat transfer model between liquid metal and shot sleeve in high pressure die casting process under non-shooting condition
}

\author{
Wen-bo Yu ${ }^{1,2}$, Yong-you Cao ${ }^{1,2}$, Zhi-peng Guo ${ }^{1,2}$, *Shou-mei Xiong ${ }^{1,2}$ \\ 1. School of Materials Science and Engineering, Tsinghua University, Beijing 100084, China \\ 2. Laboratory for Advanced Materials Processing Technology, Ministry of Education, Tsinghua University, Beijing 100084, China
}

\begin{abstract}
To predict the heat transfer behavior of A380 alloy in a shot sleeve, a numerical approach (inverse method) is used and validated by high pressure die casting (HPDC) experiment under non-shooting condition. The maximum difference between the measured and calculated temperature profiles is smaller than $3^{\circ} \mathrm{C}$, which suggests that the inverse method can be used to predict the heat transfer behavior of alloys in a shot sleeve. Furthermore, the results indicate an increase in maximum interfacial heat flux density $\left(q_{\max }\right)$ and heat transfer coefficient $\left(h_{\max }\right)$ with an increase in sleeve filling ratio, especially at the pouring zone (S2 zone). In addition, the values of initial temperature $\left(T_{\text {IDSS }}\right)$ and maximum shot sleeve surface temperature $\left(T_{\text {simax }}\right)$ at the two end zones (S2 and S10) are higher than those at the middle zone (S5). Moreover, in comparison with fluctuations in heat transfer coefficient (h) with time at the two end zones (S2 and S10), 2.4-6.5 $\mathrm{kW} \cdot \mathrm{m}^{-2} \cdot \mathrm{K}^{-1}, 3.5-12.5 \mathrm{~kW} \cdot \mathrm{m}^{-2} \cdot \mathrm{K}^{-1}$, respectively, more fluctuations are found at S5 zone, 2.1-14.7 $\mathrm{kW} \cdot \mathrm{m}^{-2} \cdot \mathrm{K}^{-1}$. These differences could theoretically explain the formation of the three zones: smooth pouring zone, un-smooth middle zone and smooth zone, with different morphologies in the metal log under the non-shot casting condition. Finally, our calculations also reveal that the values of $q_{\max }$ and $h_{\max }$ cast at $680{ }^{\circ} \mathrm{C}$ are smaller than those cast at $660^{\circ} \mathrm{C}$ and at $700^{\circ} \mathrm{C}$.
\end{abstract}

Key words: inverse method; A380 casting; filling ratio; heat transfer behavior
CLC numbers: TG146.21
Document code: $\mathrm{A}$
Article ID: 1672-6421(2016)04-269-07

\begin{abstract}
A s s one of the most cost effective near-net-shape manufacturing processes, high pressure die casting (HPDC) accounts for almost $70 \%$ of aluminum components production ${ }^{[1]}$. It has been demonstrated that the HPDC process involves rapid temperature fluctuations on the surface of the die during the fast casting cycles. This behavior could result in steep thermal gradients on and below the die surface ${ }^{[2-6]}$. According to research articles ${ }^{[7,8]}$, the solidification rate is highly dependent on the interfacial heat transfer behavior in both the shot sleeve and the die. Subsequently, solidification rate has a significant influence on the microstructural defect formation and mechanical
\end{abstract}

\footnotetext{
* Shou-mei Xiong
}

Male, Ph. D. Professor. His research interests mainly focus on $\mathrm{Al}$ and $\mathrm{Mg}$ alloy high pressure die casting and simulation.

E-mail: smxiong@tsinghua.edu.cn

Received: 2015-12-25; Accepted: 2016-02-03 properties of the final product. Furthermore, the solidification condition could affect the morphology and quantity of externally solidified crystals (ESCs) or cold flakes in the casting ${ }^{[9,10]}$. Therefore, to reduce defects in castings and achieve an optimized control condition, a thorough understanding of the heat transfer between the molten metal and the shoot sleeve is necessary.

Temperature measurement is the most difficult task in interfacial heat transfer determination in HPDC. Dour et al. ${ }^{[11]}$ pointed out that improper installation of the thermocouples could bring uncertainties in temperature measurement. To date, there are two main problems existing in casting and die temperature measurement: (I) accurate and reproducible measurements are not possible on the casting side due to the severe filling conditions, (II) the fast solidification rate in HPDC means that the thermocouples' response time and their installation in the die, including their distances from the die interface, introduce significant uncertainties in the interfacial heat transfer coefficient (IHTC) estimation. Recently, 
IHTC is generally determined by solving an inverse thermal problem. In this method, an objective function is determined based on the measured and calculated temperatures at various internal points. It is minimized or maximized as the case may be, by correcting the coefficient values used in the boundary conditions. This is carried out iteratively until a stationary value of the objective function is obtained. Thus, measurement errors can be minimized by this numerical procedure ${ }^{[12-14]}$.

Papai and Mobley ${ }^{[15]}$ determined the heat flux during the HPDC process using an iterative procedure by the inverse method. Helenrtius ${ }^{[16]}$ determined the heat transfer coefficient during the filling of molten metal inside the shot sleeve using the inverse method. However, the apparatus they used is still in a laboratory and quite different from the real case, i.e. HPDC production. In addition, there are very few studies concerning the investigation of heat transfer behavior in the shot sleeve for HPDC process. Recently, to gain a sufficiently rapid response time to follow the HPDC process and accurately measure the temperatures inside the die, a special temperature sensor unit (TSU) was designed by our group. By using this TSU, temperatures at 1, 3 and $6 \mathrm{~mm}$ from the interface were measured inside the die, corresponding to each location ${ }^{[17,18]}$. Then, the calculated results were compared to the experimental measurements. In this way, the inverse method was modified and corrected.

In this work, to study the interfacial heat transfer behavior between metal and shot sleeve, a specially designed shot sleeve and A380 alloy were used in the HPDC experiment on a 350ton cold chamber die-casting machine under non-shot condition. Based on the measured temperature, the inverse method was used to simulate the interfacial heat transfer behavior in the shot sleeve under non-shot condition. Furthermore, the effect of sleeve filling ratio and pouring temperature on interfacial heat transfer behavior were also studied.

\section{Experimental and theoretical procedures}

\subsection{Experimental casting and sensor installation}

The experiment was performed on a TOYO 350 ton die casting machine under non-shot conditions (via the plunger), as shown in Fig. 1. The specially designed shot sleeve made of H13 steel has an internal diameter of $60 \mathrm{~mm}$, thickness of $22.5 \mathrm{~mm}$ and length of $405 \mathrm{~mm}$. The shot sleeve was instrumented with three blocks of thermocouples in the bottom side along the movement direction of the plunger to collect temperature readings at the metal-sleeve interface. The thermocouple probes were placed in three different positions: (1) the pouring zone where the melt hit the sleeve, (2) the middle zone, and (3) the end zone where the melt was injected to the runner. Each of these thermocouple probes comprised of three pairs of K-type thermocouple with $0.045 \mathrm{~mm}$ in wire diameter. The diameter of probe, sheathed with stainless steel, is $0.500 \mathrm{~mm}$. The temperature measuring points were inside the sleeve wall and placed 1,3, and $6 \mathrm{~mm}$ from the metal-sleeve interface. Real-time temperature data were then recorded using a Spartan data logging system (96 isolated analog inputs channels) manufactured by the Integrated Measurement Corporation with a sampling rate of $500 \mathrm{~Hz}$. The A380 alloy was melted and delivered to the shot sleeve through the heated feeding pipe. The compositions and thermal properties of A380 alloy and H13 steel are shown in Tables 1 and 2, respectively.

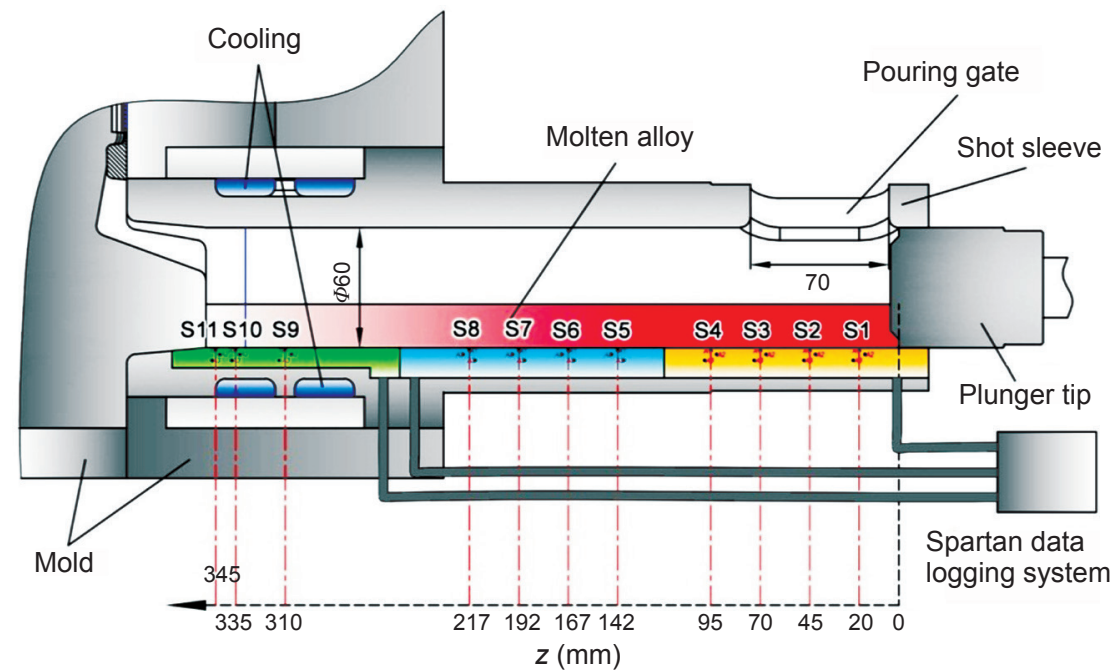

Fig. 1: Schematic of experimental setup

Table 1: Chemical compositions of A380 alloy and H13 steel (wt.\%).

\begin{tabular}{|c|c|c|c|c|c|c|c|c|c|}
\hline \multirow{2}{*}{ A380 } & Si & $\mathrm{Cu}$ & $\mathrm{Fe}$ & $\mathrm{Zn}$ & Mn & $\mathrm{Mg}$ & $\mathrm{Ni}$ & $\mathrm{Ti}$ & Al \\
\hline & 9.87 & 2.93 & 0.66 & 0.47 & 0.22 & 0.18 & 0.06 & 0.03 & Bal. \\
\hline \multirow{2}{*}{ H13 } & C & Mn & $\mathrm{Si}$ & $s$ & $\mathbf{P}$ & $\mathrm{Cr}$ & Mo & V & $\mathrm{Fe}$ \\
\hline & 0.396 & 0.36 & 0.94 & $<0.005$ & $<0.025$ & 5.05 & 1.25 & 0.82 & Bal. \\
\hline
\end{tabular}


Table 2: Thermal properties of A380 alloy and $\mathrm{H} 13$ steel

$\begin{array}{ccccccc}\begin{array}{c}\text { Thermal } \\ \text { properties }\end{array} & \begin{array}{c}\text { Thermal } \\ \text { conductance } \\ \boldsymbol{\lambda}\left(\mathbf{W} \cdot \mathbf{m}^{-1} \cdot \mathbf{K}^{-1}\right)\end{array} & \begin{array}{c}\text { Specific heat } \\ \boldsymbol{C}_{\mathrm{p}}\left(\mathbf{J} \cdot \mathbf{k g}^{-1} \cdot \mathbf{K}^{-1}\right)\end{array} & \begin{array}{c}\text { Density } \\ \boldsymbol{\rho}\left(\mathbf{k g} \cdot \mathbf{m}^{-3}\right)\end{array} & \begin{array}{c}\text { Solidus } \\ \text { temperature } \\ \boldsymbol{T}_{\mathrm{S}}\left({ }^{\circ} \mathbf{C}\right)\end{array} & \begin{array}{c}\text { Liquidus } \\ \text { temperature } \\ \boldsymbol{T}_{\mathrm{L}}\left({ }^{\circ} \mathbf{C}\right)\end{array} & \begin{array}{c}\text { Latent heat } \\ \mathbf{L}_{\mathrm{s}}\left(\mathbf{J} \cdot \mathbf{k g}^{-1}\right)\end{array} \\ \text { A380 } & 96.2 & 963 & 2,710 & 540 & 595 & 389,000 \\ \text { H13 } & 31.2-0.013 \boldsymbol{T} & 478-0.219 \boldsymbol{T} & 7,730-0.24 \boldsymbol{T} & 1,471 & 1,404 & 209,350\end{array}$

${ }^{*} \boldsymbol{T}$ stands for temperature $\left({ }^{\circ} \mathrm{C}\right)$.

\subsection{Numerical approaches (inverse method)}

The inverse method utilizes the known temperatures at measurement points on the outer wall to estimate the heat convection coefficient $\left(q_{M}\right)$, fluid temperature and wall temperature on the inner wall. The inverse problem can be mathematically transformed into an optimization problem as follows ${ }^{[12]}$ :

$$
F\left(q_{M}\right)=\sum_{j=1}^{J} \sum_{i=1}^{R}\left(T_{j, M+i}-Y_{j, M+i}\right)^{2} \rightarrow \min
$$

where $i$ and $j$ are the position and time of temperature measurement, $T$ and $Y$ are the calculated and experimental temperatures, respectively. $R$ is the measurement point number of the outer wall, and $J$ is the time step number.

\subsection{Liquid metal temperature resolves in sleeve}

To evaluate the exact mathematical solutions to twodimensional (2D), the following equation is adopted ${ }^{[19]}$ :

$$
\frac{\partial}{\partial z}\left(\lambda \frac{\partial T}{\partial z}\right)+\frac{\partial}{\partial x}\left(\lambda \frac{\partial T}{\partial z}\right)+\rho L \frac{\partial f_{s}}{\partial t}=\rho C_{p} \frac{\partial T}{\partial t}
$$

where $C_{p}$ is the specific heat capacity, $\rho$ is the density, and $\lambda$ is the thermal conductivity, $\rho L \partial f_{s} / \partial t$ is the heat latent release in metal solidification.

To eliminate the nonlinear of $\lambda$ and $C_{p}$, Kirchhoff transformation and equivalent specific heat were adopted with the following equations:

$$
\begin{gathered}
C_{p e}=C_{p}-L \frac{\partial f_{s}}{\partial T} \\
U=\frac{1}{\lambda_{0}} \int_{T_{0}}^{T} \lambda d T
\end{gathered}
$$

where $\lambda_{0}$ is the thermal conductivity at the reference temperature, $T_{0}$; then, equation (2) is transformed into a linear equation concerning temperature replacement, $U$. Given by

$$
\begin{gathered}
\frac{\partial^{2} U}{\partial z^{2}}+\frac{\partial^{2} U}{\partial x^{2}}=\frac{1}{\alpha_{1}} \frac{\partial U}{\partial t} \\
\alpha_{1}=\frac{\lambda}{\rho C_{p e}}
\end{gathered}
$$

Through alternating the implicit difference, the time step from $t_{\mathrm{k}}$ to $t_{\mathrm{k}+1}$ are divided into two sections. At $t_{\mathrm{k}+0.5}$ and $t_{\mathrm{k}+1}$ time, the equation is applied alternately along $r$ and $z$ implicit direction under different format in the node $(i, j)$, and then the liquid metal temperature in the sleeve can be calculated through catching Method Iterative.

$$
\begin{aligned}
& \left\{\begin{array}{l}
-f_{z} U_{i-1, j}^{k+0.5}+2\left(1+f_{z}\right) U_{i, j}^{k+0.5}-f_{z} U_{i+1, j}^{k+0.5}= \\
f_{x} U_{i, j-1}^{k}+2\left(1-f_{x}\right) U_{i, j}^{k}+f_{x} U_{i, j+1}^{k} \\
-f_{x} U_{i, j-1}^{k+1}+2\left(1+f_{x}\right) U_{i, j}^{k+1}-f_{x} U_{i, j+1}^{k+1}= \\
f_{z} U_{i-1, j}^{k+0.5}+2\left(1-f_{z}\right) U_{i, j}^{k+0.5}+f_{z} U_{i+1, j}^{k+0.5}
\end{array}\right. \\
& f_{z}=\frac{\alpha_{1} \Delta t}{\Delta z^{2}}, f_{x}=\frac{\alpha_{1} \Delta t}{\Delta x^{2}}
\end{aligned}
$$

Combined with the aforementioned assumptions of casting sleeve, boundary conditions between the liquid metal and the sleeve interface are as follows:

$$
-\left(\lambda \frac{\partial T}{\partial x}\right)_{i, N}^{k+1}=q_{i}
$$

Because the upper liquid metal contacts with the air in the casting sleeve, its heat transfer boundary condition is regarded as radiation convection, as follows:

$$
\begin{aligned}
-\left(\lambda \frac{\partial T}{\partial x}\right)_{i, M}^{k+1} & =q_{\mathrm{r}}=q_{\mathrm{c}}+q_{\mathrm{R}} \\
& =h\left(T_{\mathrm{mu}}-T_{\mathrm{air}}\right)+\varepsilon \sigma\left(T_{\mathrm{mu}}^{4}-T_{\text {air }}^{4}\right)
\end{aligned}
$$

where $q_{\mathrm{r}}, q_{\mathrm{c}}, q_{\mathrm{R}}$ are the heat density, radiation and convection coefficient of upper liquid metal, respectively. $T_{\mathrm{mu}}$ is the temperature of upper of liquid metal, $T_{\text {air }}$ is the environmental temperature above the upper liquid metal, $\sigma=5.67 \times 10^{-8} \mathrm{~W} \cdot \mathrm{m}^{-2} \cdot \mathrm{K}^{-4}$ is Stephen-Boltzman coefficient, $\varepsilon$ is the total value of radiation and convection coefficients, which is 0.12 for $\mathrm{Al}$ alloy.

\subsection{Pressure chamber wall temperature}

At the interface between the melt and shot sleeve, there is no latent heat release. According to Fig. 2, one-dimensional heat equation can be written as:

$$
\frac{\partial}{\partial x}\left(\lambda \frac{\partial T}{\partial x}\right)=\rho C_{p} \frac{\partial T}{\partial t}
$$

With the substitution of equation (4):

$$
\frac{\partial^{2} U}{\partial x^{2}}=\frac{1}{\alpha} \frac{\partial U}{\partial t}
$$

where $\alpha=\lambda / \rho C_{p}$. Then, implicit finite difference is used to calculate discretization for equation (12), so that the sleeve and melt interface temperature can be calculated through Catching Method Iterative: 


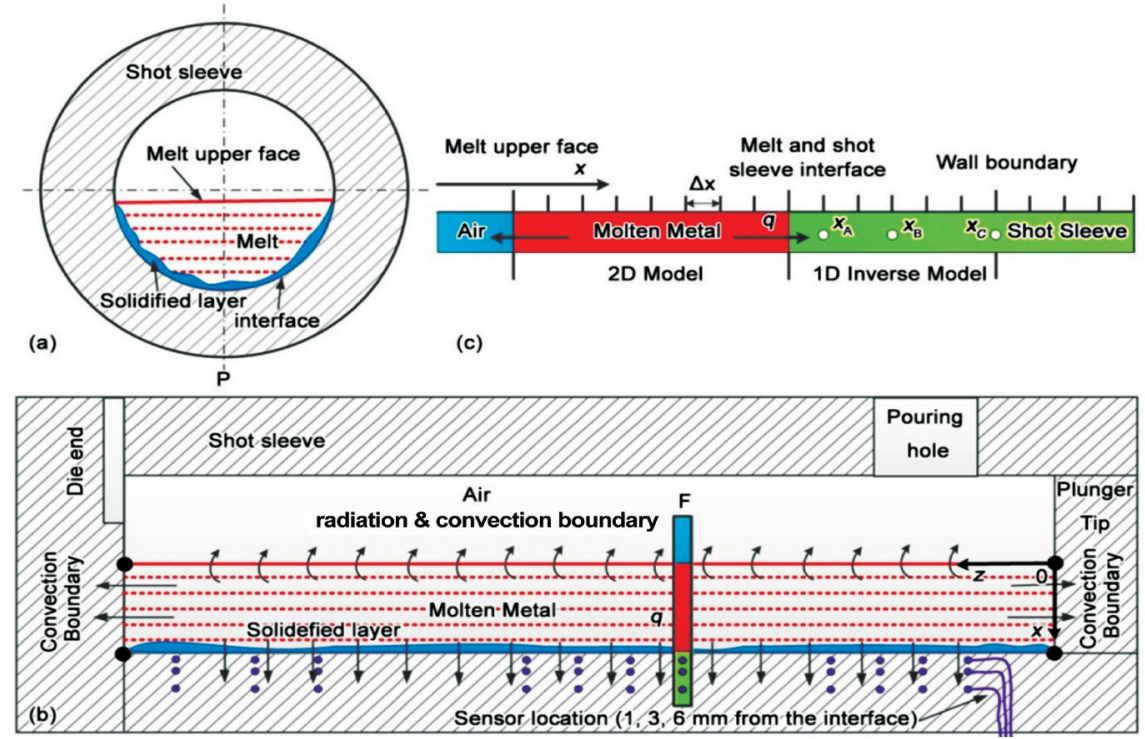

Fig. 2: Configuration and boundary conditions of shot sleeve: (a) cross section, (b) longitude section and (c) heat transfer model, which is the enlarged area marked as $F$ in (b)

$$
\begin{gathered}
-U_{i-1}^{k+1}+\left(2+R_{F o}\right) U_{i}^{k+1}-U_{i+1}^{k+1}=R_{F o} U_{i}^{k} \\
R_{F o}=\frac{\Delta x^{2}}{\alpha \Delta t}=\frac{\rho C_{p}}{\lambda_{0}} \frac{\Delta x^{2}}{\Delta t}
\end{gathered}
$$

\section{Results and discussion}

\subsection{Comparison between measurements and calculated results using inverse method}

Figure 3 shows the temperature and heat transfer coefficient calculated using the inverse method at the middle zone (S5 in Fig. 1) in the third casting cycle at pouring temperature $680^{\circ} \mathrm{C}$. It can be seen that the measured and calculated temperature curves at 3 $\mathrm{mm}$ below the interface of the shot sleeve are almost overlapped. The maximum difference between the measured and calculated temperature profiles never exceeds $3{ }^{\circ} \mathrm{C}$, which indicates that the inverse estimation results are quite accurate. During the casting procedure, the poured liquid metal temperature $\left(T_{\mathrm{mi}}\right)$ decreased very quickly from the pouring gate $\left(680^{\circ} \mathrm{C}\right)$ to the middle zone (below $595^{\circ} \mathrm{C}$ ) in $0.67 \mathrm{~s}$ due to the heat absorption by the sleeve interface. Herein, the cooling rate can be extracted, which is about $125.7^{\circ} \mathrm{C} \cdot \mathrm{s}^{-1}$. Then, with the entrance of more liquid metal, the $T_{\mathrm{mi}}$ increased again to above the liquidus $\left(595^{\circ} \mathrm{C}\right)$. At the same time, the interfacial heat flux density $\operatorname{IHFD}(q)$ and interfacial heat transfer coefficient IHTC $(h)$ rose immediately to the peak value, about $2.51 \mathrm{MW} \cdot \mathrm{m}^{-2}$ and $13.7 \mathrm{MW} \cdot \mathrm{m}^{-2} \mathrm{~K}^{-1}$, respectively.

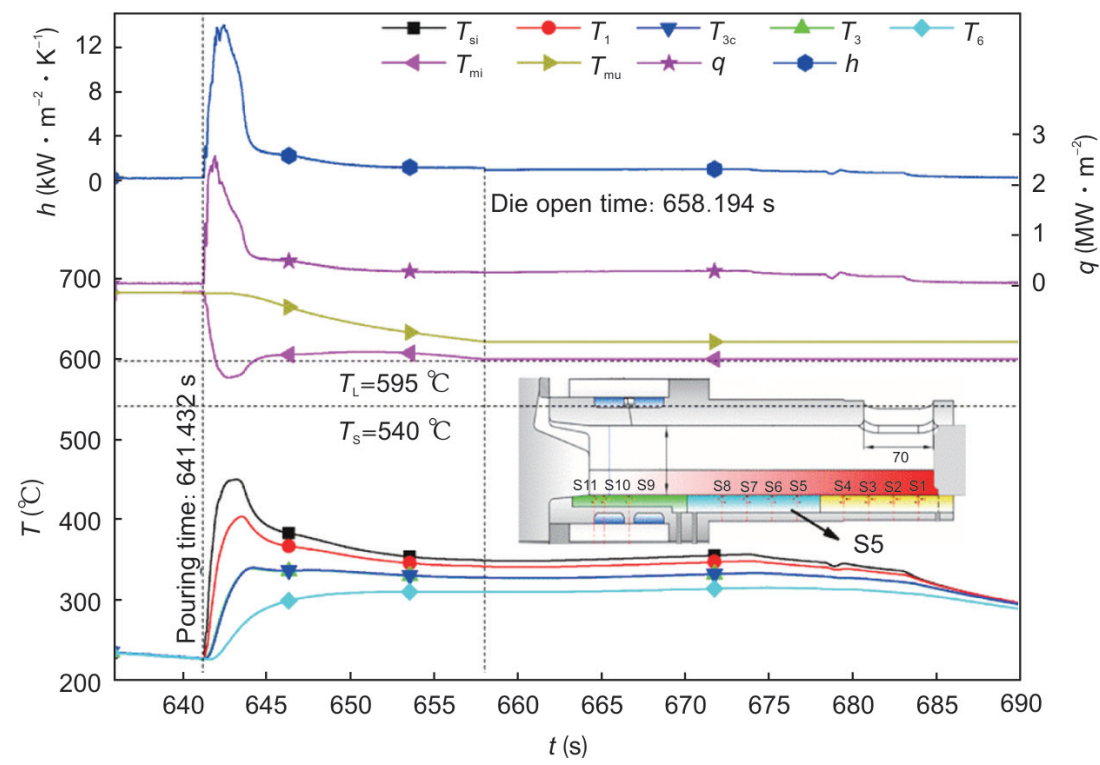

Fig. 3: Typical calculated and measured results of shot sleeve at S5 position during 3th cycle under non-shot condition $\left(T_{\mathrm{mu}}, T_{\mathrm{mi}}\right.$ - temperatures at casting metal upper surface and interface between melt and sleeve; $T_{\mathrm{si}}$ - shot sleeve surface temperature; $T_{1}, T_{3}, T_{6}$ - measured temperatures at 1,3 and $6 \mathrm{~mm}$ from interface in shot sleeve; $h$ - interfacial heat transfer coefficient; $q$ - interfacial heat flux density; $T_{3 c}$ - calculated temperature at $3 \mathrm{~mm}$ from interface in shot sleeve) 


\subsection{Effect of filling ratio in shot sleeve on IHTC}

In order to analyze the effect of sleeve filling ratios on interfacial heat transfer coefficient (IHTC, $h$ ), five group experiments with different filling ratios $(21.8 \%, 27.5 \%, 33.2 \%$, $38.9 \%$ and $44.7 \%$ ) were chosen to perform the non-shot casting under pouring temperature of $680{ }^{\circ} \mathrm{C}$, with a residence time of $15 \mathrm{~s}$ in the shot sleeve. Three successive casting cycles were carried out for each group, and the third cycle in each group was chosen for comparing the variation of $h$ under different sleeve filling ratios.

Figure 4 shows the variation of calculated shot sleeve surface temperature at three positions (S2, S5 and S10) along the longitudinal direction in the third casting cycle. As can be seen, the sleeve surface temperature curves almost have the same trend from the pouring gate zone to the end zone with different sleeve chamber filling ratios. However, the chamber surface temperature with the higher sleeve filling ratios $(38.9 \%$ and $44.7 \%)$ is higher than those of lower filling ratios $(21.8 \%$ and $27.5 \%$ ), especially, at S2 and S5 zones. Furthermore, the variation of sleeve surface temperature is not significant at the lower sleeve filling ratios, between $21.8 \%-33.2 \%$ in this study.

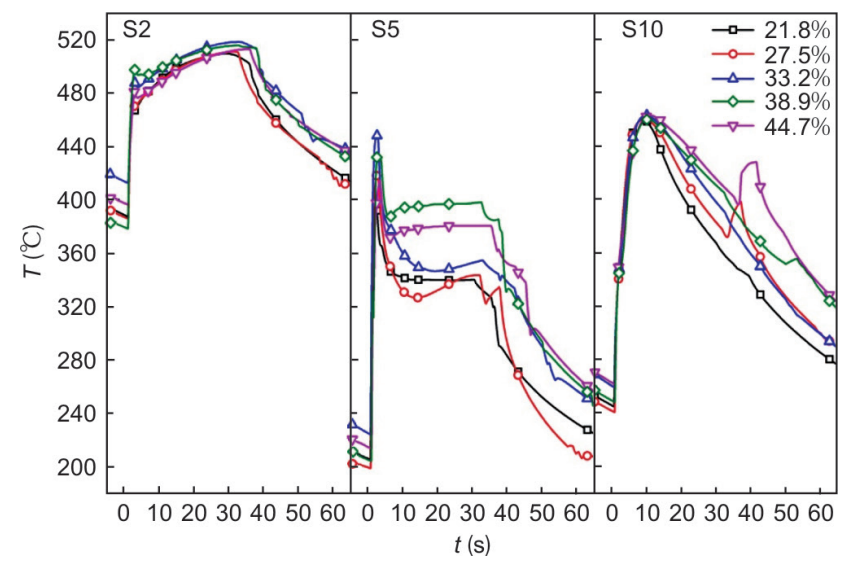

Fig. 4: Calculated sleeve surface temperature at third casting cycle at three positions (S2, S5 and S10) along longitudinal direction with different sleeve filling ratios

Furthermore, the shot sleeve surface temperature at S2 zone and S10 zone is higher than that at S5 zone in each cycle. This phenomenon can be explained from the movement of molten metal in the shot sleeve. Firstly, hot liquid metal was poured into the shot sleeve from the pouring gate, which results in the initial peak of the sleeve surface temperature at pouring gate zone (S2). Secondly, this relatively fast filling velocity aroused the melt splash and turbulence accompanied with the liquid metal flow, which results in one non-closed contact between the liquid metal and sleeve surface, so the peak of sleeve interfacial temperature at the sleeve middle zone (S5) is lower than that of pouring gate. However, the liquid metal continues to flow forward and becomes stable at the end zone (S10) of shot sleeve, which allows the liquid metal and the shot sleeve surface to form one close contact. Therefore, the end zone (S10) of the shot sleeve has a higher temperature peak than the middle zone. Finally, this movement of the liquid metal in the sleeve could result in different morphology at S2, S5 and S10 zone of the metal log. Figure 5 shows the front and back surfaces of solidified metal $\log$ in the 3 rd cycle cast with a filling ratio $27.5 \%$. Apparently, the back surface that contacted with the sleeve interior surface can be divided into three parts: smooth pouring zone, un-smooth middle zone and smooth end zone.

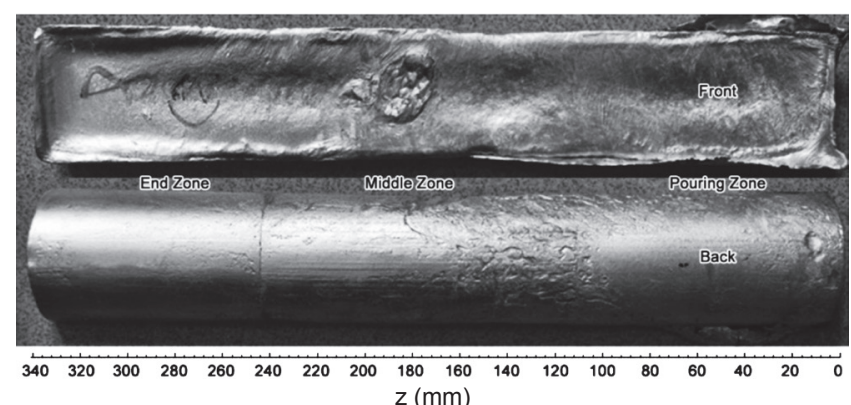

Fig. 5: Solidified metal log in 3rd casting cycle under nonshooting condition with a filling ratio of $27.5 \%$

Figure 6 shows the variation of calculated IHTDs $(q)$ and IHTCs $(h)$ with time at three positions (S2, S5 and S10 zones) along the longitudinal direction under different sleeve filling ratios in the third casting cycle. At the pouring gate zone (S2), the $q$ and $h$ reached the peaks when the liquid metal contacts with the sleeve surface, followed by a serious decrease and a smooth platform. It should be pointed out that the $q$ and $h$ with sleeve filling ratio of $44.7 \%$ are much higher than the other cases. At the middle zone, compared to the pouring gate zone and end zone of the shot sleeve, the highest $q$ and $h$ peaks indicate a strong heat transfer. Furthermore, larger fluctuations of $q$ and $h$ occurred at S5 in comparison with S2 and S10. In Fig. 5, the un-smooth middle surface suggests a non-constant contact between liquid metal and sleeve shot surface. This can be attributed to the previous solidified metal, which resulted in the fluctuations of $q$ and $h$. At the end zone, two peaks in $q$ or $h$ curves appeared, especially for $q$. This phenomenon can be explained by the liquid metal flow movement. At the beginning, the liquid metal reached this area and solidified to form one solid layer, which decreased the heat transfer efficiency. When more liquid metal reached this area, the previously solidified layer was melted again; the heat transfer efficiency was increased again, and therefore, the $q$ and $h$ values increased again. Furthermore, it should be noted that the first peak in $q$ or $h$ becomes less remarkable with the increasing sleeve filling ratio. This can be ascribed to the less formed solidified layer with the higher quantity of pouring liquid metal.

To clarify the effect of sleeve filling ratios on the initial temperature ( $T_{\text {IDS }}$ ) and maximum shot sleeve surface temperature $\left(T_{\text {simax }}\right)$, the statistic results are given in Fig. 7. The values of $T_{\text {IDS }}$ and $T_{\text {simax }}$ at S2 and S10 are higher than that of S5 in each filling ratio. This further confirms that the back surface in contact withthe sleeve interior surface can be divided into three parts, as given in Fig. 5. 

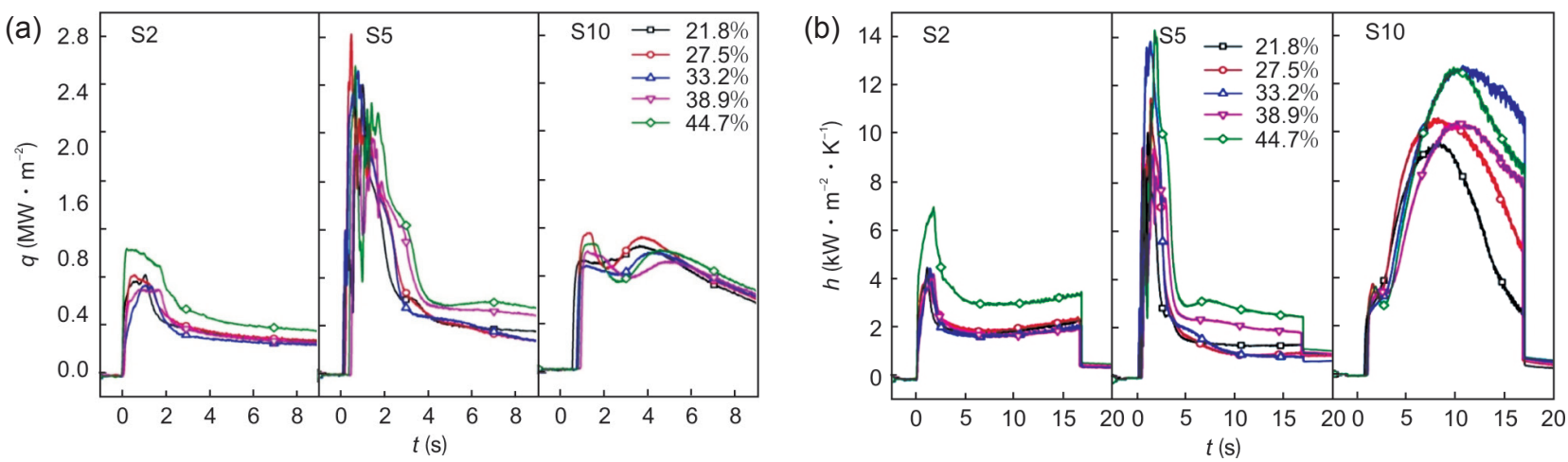

Fig. 6: Variation of calculated IHTDs $(q)$ and IHTCs $(h)$ with time at three positions $(S 2, S 5$ and S10) along longitudinal direction in different sleeve filling ratios in third casting cycle
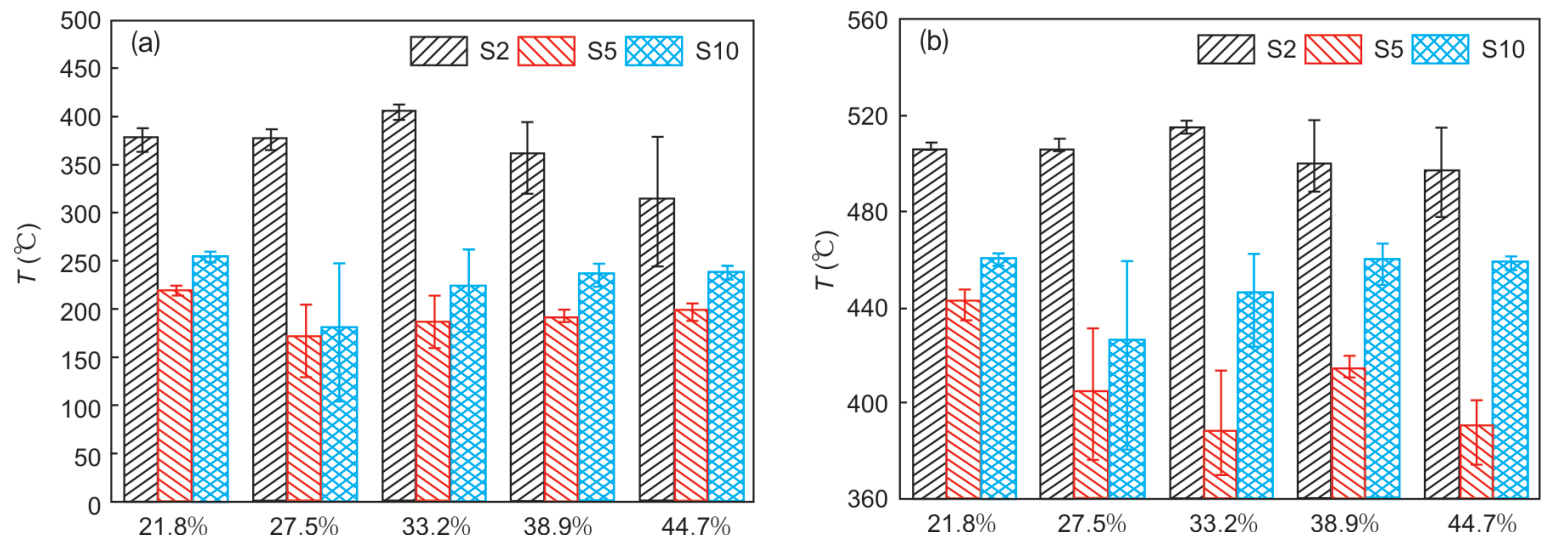

Fig. 7: Statistics of calculated values under different sleeve filling ratios at three positions (S2, S5 and S10) in third casting cycle: (a) $T_{\mathrm{IDS}}$ and (b) $T_{\text {simax }}$

\subsection{Effect of pouring temperature in shot sleeve on IHTC}

To clarify the effect of pouring temperature on $q$, three pouring temperatures were adopted: $660{ }^{\circ} \mathrm{C}, 680{ }^{\circ} \mathrm{C}$ and $700{ }^{\circ} \mathrm{C}$. The calculated maximum interfacial heat transfer coefficient $\left(h_{\text {max }}\right)$, maximum heat flow density $\left(q_{\max }\right)$, the initial temperature $\left(T_{\mathrm{IDS}}\right)$ and maximum shot sleeve surface temperature $\left(T_{\text {simax }}\right)$ with the same filling ratio $(33.2 \%)$ are given in Fig. 8. Figure 8(a) and (b) show that the values of $q_{\max }$ and $h_{\max }$ cast at $680{ }^{\circ} \mathrm{C}$ are smaller than those cast at $660{ }^{\circ} \mathrm{C}$ and $700{ }^{\circ} \mathrm{C}$. Furthermore, as shown in Fig. 8 (c) and (d), the values of $T_{\mathrm{IDS}}$ and $T_{\text {simax }}$ at S2 and S10 are higher than those of S5 along S2 to S10 direction at $660^{\circ} \mathrm{C}$ and $680{ }^{\circ} \mathrm{C}$. However, when the liquid metal pouring temperature reached $700{ }^{\circ} \mathrm{C}$, the $T_{\text {simax }}$ decreased successively along S2 to S10 direction.

\section{Conclusions}

In this study, a numerical approach (inverse method) is carried out and confirmed with the measured temperature in high pressure casting of A380 alloy. The heat transfer behavior of A380 alloy under different pouring temperatures and sleeve filling ratios under non-shot casting conditions in HPDC has been carefully studied. The following conclusions were drawn:

(1) Compared to the heat transfer coefficient $(h)$ fluctuations with time at two end zones (S2 and S10), 2.4-6.5 $\mathrm{kW} \cdot \mathrm{m}^{-2} \cdot \mathrm{K}^{-1}$ and $3.5-12.5 \mathrm{~kW} \cdot \mathrm{m}^{-2} \cdot \mathrm{K}^{-1}$, respectively, more fluctuations were found at $\mathrm{S} 5$ zone, $2.1-14.7 \mathrm{~kW} \cdot \mathrm{m}^{-2} \cdot \mathrm{K}^{-1}$. These calculations theoretically explain the formation of three zones in the metal log in non-shot casting condition, especially, the coarse middle zone.

(2) The maximum interfacial heat flux density $\left(q_{\max }\right)$ and heat transfer coefficient $\left(h_{\max }\right)$ become higher with increasing sleeve filling ratio, especially at $\mathrm{S} 2$ zone with the filling ratio of $44.7 \%$. Furthermore, in all of the sleeve filling ratios, the values of initial temperature $\left(T_{\mathrm{IDS}}\right)$ and maximum shot sleeve surface temperature $\left(T_{\text {simax }}\right)$ are higher than those of S5 along $\mathrm{S} 2$ to $\mathrm{S} 10$ direction.

(3) Concerning the effect of pouring temperature, the values of $q_{\max }$ and $h_{\max }$ pouring at $680{ }^{\circ} \mathrm{C}$ are smaller than those pouring at $660{ }^{\circ} \mathrm{C}$ and $700{ }^{\circ} \mathrm{C}$. Furthermore, the values of $T_{\text {IDS }}$ and $T_{\text {simax }}$ at $\mathrm{S} 2$ and $\mathrm{S} 10$ are higher than those of S5 along $\mathrm{S} 2$ to $\mathrm{S} 10$ direction at $660{ }^{\circ} \mathrm{C}$ and $680{ }^{\circ} \mathrm{C}$. When the liquid metal pouring temperature reaches $700{ }^{\circ} \mathrm{C}$, the $T_{\text {simax }}$ decreases successively along S2 to S10 direction.

\section{References}

[1] Andresen W. Die Cast Engineering: A Hydraulic, Thermal, and Mechanical Process: CRC Press, Taylor and Francis Group, New York, 2004.

[2] Klobčar $D$, Tušek J. Thermal stresses in aluminium alloy die casting dies. Computational Materials Science, 2008, 43: 1147-1154. 

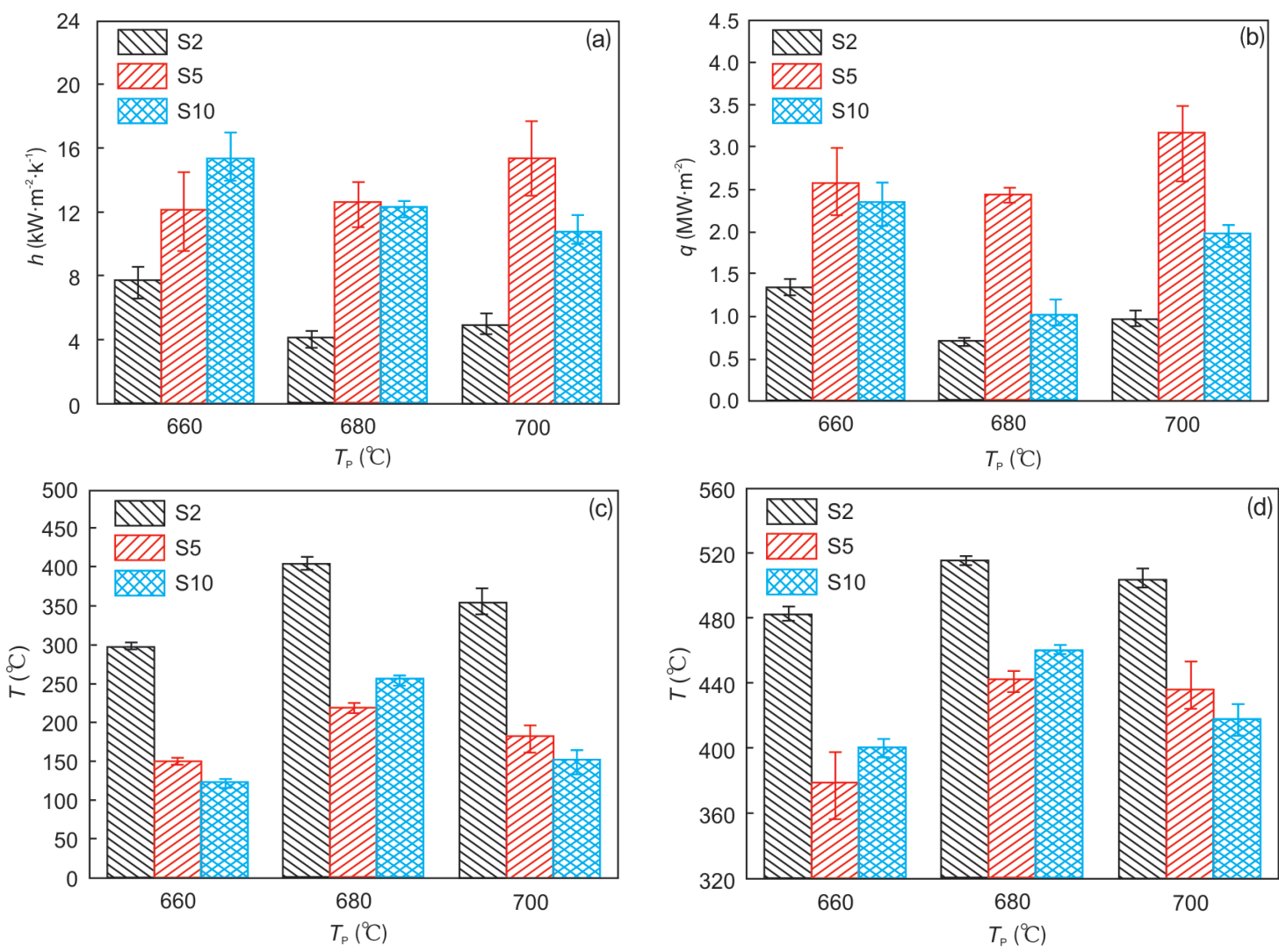

Fig. 8: Statistics of calculated values under different pouring temperatures at three positions (S2, S5 and S10) in third casting cycle: (a) $h_{\max }$, (b) $q_{\max }$, (c) $T_{\text {IDS }}$ and (d) $T_{\text {simax }}$

[3] Jia L, Xiong S M, Liu B C. Study on numerical simulation of mold filling and heat transfer in die casting process. Journal of Materials Science and Technology, 2000,16: 269-272.

[4] Zhang W S, Xiong S M, Liu B C. Study on a CAD/CAE system of die casting. Journal of Materials Processing Technology 1997, 63: 707-711

[5] Xiong S M and Liu B C. Study on numerical simulation of moldfilling and solidification processes of shaped casting. Chinese Journal of Mechanical Engineering (English Edition), 1999, 12(1): 4-10.

[6] Wu M W, Xiong S. Microstructure Characteristics of the Eutectics of Die Cast AM60B Magnesium Alloy. Journal of Materials Science \& Technology, 2011, 27: 1150-1155.

[7] Song J, Xiong S M, Li M, et al. The correlation between microstructure and mechanical properties of high-pressure diecast AM50 alloy. Journal of Alloys and Compounds, 2009, 477: 863-871.

[8] Song J, Xiong S M, Li M, et al. In situ observation of tensile deformation of high-pressure die-cast specimens of AM50 alloy. Materials Science and Engineering: A, 2009, 520: 197-201.

[9] Guo Z P, Xiong S M, Liu B C, et al. Effect of process parameters, casting thickness, and alloys on the interfacial heat-transfer coefficient in the high-pressure die-casting process. Metallurgical and Materials Transactions A, 2008,39: 2896-2905.

[10] Yu W, Cao Y, Li X, et al. Determination of Interfacial Heat Transfer Behavior at the Metal/Shot Sleeve of High Pressure Die Casting Process of AZ91D Alloy. Journal of Materials Science \& Technology, DOI: http://dx.doi.org/10.1016/j.jmst.2016.02.003.

[11] Dour G, Dargusch M, Davidson C. Recommendations and guidelines for the performance of accurate heat transfer measurements in rapid forming processes. International Journal of Heat and Mass Transfer, 2006, 49: 1773-1789.

[12] Beck J V. Nonlinear estimation applied to the nonlinear inverse heat conduction problem. International Journal of Heat and Mass Transfer, 1970, 13: 703-716.

[13] Beck J V, Blackwell B, Clair Jr CRS. Inverse Heat Conduction: III-Posed Problems. John Wisley \& Sons. Inc, 1985, 56323: 8535-5391.

[14] Garcia A, Clyne T, Prates M. Mathematical model for the unidirectional solidification of metals: II. Massive molds. Metallurgical Transactions B, 1979, 10: 85-92.

[15] Papai J, Mobley C. Die thermal fields and heat fluxes during die casting of 380 aluminum alloy in $\mathrm{H}-13$ steel dies. Proceedings of the NADCA Congress and Exposition, Detroit, 1991.

[16] Helenius R, Lohne O, Arnberg L, et al. The heat transfer during filling of a high-pressure die-casting shot sleeve. Materials Science and Engineering: A, 2005, 413: 52-56.

[17] Guo Z P, Xiong S M, Liu B C, et al. Determination of the heat transfer coefficient at metal-die interface of high pressure die casting process of AM50 alloy. International Journal of Heat and Mass Transfer, 2008, 51: 6032-6039.

[18] Guo Z P, Xiong S M, Cho S H, et al. Development of an inverse heat transfer model and its application in the prediction of the interfacial heat flux. Acta Metallurgica Sinica, 2007, 43: 607. (In Chinese)

[19] Bonani F, Ghione G. On the application of the Kirchhoff transformation to the steady-state thermal analysis of semiconductor devices with temperature-dependent and piecewise inhomogeneous thermal conductivity. Solid-state Electronics, 1995, 38: 1409-1420. 